\title{
Effectiveness and Safety of Etanercept in Patients with Psoriatic Arthritis in a Canadian Clinical Practice Setting: The REPArE Trial
}

\author{
DAFNA D. GLADMAN, CLAIRE BOMBARDIER, CARTER THORNE, BOULOS HARAOUI, MAJED KHRAISHI, \\ PROTON RAHMAN, WILLIAM BENSEN, JERRY SYROTUIK, and MELANIE POULIN-COSTELLO
}

\begin{abstract}
Objective. To describe the longterm effectiveness and safety of etanercept in Canadian patients with psoriatic arthritis (PsA), treated over 24 months in clinical practice.

Methods. Patients with active PsA ( $\geq 3$ tender and $\geq 3$ swollen joints) were recruited from 22 centers. Etanercept was administered at $50 \mathrm{mg} /$ week subcutaneously. In addition to clinical assessment of skin and joint disease, conducted at baseline and at Months 6, 12, 18, and 24, regular patient interviews were conducted by telephone. Patient responses related to health status, disability, and work productivity were scored using the patient global assessment tool, the Health Assessment Questionnaire (HAQ), the Health and Labour Questionnaire (HLQ), and the Fatigue Severity Scale. Results. Out of 110 patients, 71 (65\%) maintained etanercept treatment through the end of our study. All clinical measures of disease severity, including joint tenderness/pain, joint swelling, and Psoriasis Area and Severity Index score, improved significantly between baseline and Month 6 of etanercept treatment and remained constant thereafter. By the end of our study, $79 \%$ of patients achieved a Psoriatic Arthritis Response Criteria response, and 56\% of patients achieved a 0.5 -point improvement on HAQ, indicating clinically significant improvement in disability; $14 \%$ of patients finished our study free of disability $(\mathrm{HAQ}=0)$. Patients' work productivity and fatigue improved significantly in parallel with these clinical and functional improvements.

Conclusion. Continuous treatment with etanercept over 2 years in a clinical setting improved clinical symptoms of PsA while reducing fatigue, improving work productivity, and ameliorating or eliminating disability. (First Release May 15 2011; J Rheumatol 2011;38:1355-62; doi:10.3899/ jrheum.100698)
\end{abstract}

\section{Key Indexing Terms: TUMOR NECROSIS FACTOR INHIBITORS ETANERCEPT CLINICAL TRIALS}

\section{PSORIATIC ARTHRITIS} PRODUCTIVITY
Psoriatic arthritis (PsA) is an inflammatory arthritis with a variable course, associated with psoriasis. It is often erosive and may result in joint deformities and functional disability ${ }^{1}$. PsA is typically seronegative and can be distinguished

From Toronto Western Hospital (University of Toronto) and University Health Network, Toronto; Southlake Regional Health Centre, Newmarket; McMaster University, Hamilton; Amgen Canada Inc., Mississauga, Ontario; Institut de Rhumatologie de Montréal, Université de Montréal, Montréal, Québec; and Memorial University of Newfoundland, St. John's, Newfoundland and Labrador, Canada.

Funded by Amgen Canada Inc. and Wyeth, a Pfizer company. D.D. Gladman, MD, FRCPC, Toronto Western Hospital, University of Toronto; C. Bombardier, MD, FRCPC, University Health Network; C. Thorne, MD, Southlake Regional Health Centre; B. Haraoui, MD, FRCPC, Institut de Rhumatologie de Montréal, Université de Montréal; M. Khraishi, MB, BCh, FRCPC, Memorial University of Newfoundland; P. Rahman, MD, MSc, FRCPC, Memorial University of Newfoundland; W. Bensen, MD, FRCPC, McMaster University; J. Syrotuik, MA; M. Poulin-Costello, MSc, PStat, Amgen Canada Inc.

Address correspondence to Dr. D.D. Gladman, Toronto Western Hospital, 399 Bathurst Street, 1E-410B, Toronto, Ontario M5T 2S8, Canada.

E-mail:dafna.gladman@utoronto.ca

Full Release Article. For details see Reprints/Permissions at jrheum.org Accepted for publication February 8, 2011. from rheumatoid arthritis (RA) on the basis of clinical features, but it is associated with radiographic damage and risk of deformity similar to those seen in $\mathrm{RA}^{2,3}$. Prevalence of PsA among individuals with psoriasis, who may number about 500,000 in Canada ${ }^{4}$, is variably estimated, depending on the population and the diagnostic criteria used. Numbers from the United States suggest that $9 \%-14 \%$ of patients with psoriasis develop PsA ${ }^{5}$. This disease is thought to be underdiagnosed in Canada ${ }^{6}$ and elsewhere ${ }^{7}$.

Severe PsA is associated with significant degradation of quality of life, as a result of cutaneous and articular symptoms. Even uncomplicated psoriasis can be painful, itchy, or debilitating, and it may be socially isolating because of stigmatization and comorbid anxiety and depression ${ }^{4}$. The burden of illness in PsA appears to be greater still ${ }^{6}$. Quality-of-life studies indicate that PsA significantly reduced all components of physical and mental well-being, relative to the general population ${ }^{8,9,10}$. Compared with other inflammatory rheumatic diseases, such as RA and ankylosing spondylitis, the extent of this effect was similar for physical components such as physical functioning, limitations 
due to physical function, and bodily pain. The effect of PsA on mental components was significantly influenced by the severity of patients' skin symptoms ${ }^{8}$.

PsA is also significantly debilitating, as demonstrated in a recent Norwegian study in which $33 \%$ of women and $17 \%$ of men with PsA were identified as work-disabled ${ }^{11}$. Predictors of disability among patients with PsA included disease duration, presence of erosive disease, and patient score on a modified version of the widely used Health Assessment Questionnaire (HAQ). The HAQ has been validated in studies of PsA and RA as a quantitative measure of disability in activities of daily living (hygiene, activities, reach, walking, eating, arising, grip, and dressing and grooming), before and after treatment with various therapeutics $^{12,13}$. The Health and Labour Questionnaire (HLQ) is a related tool, focusing on work performance and the impediments that patients experience to performing paid and unpaid labor ${ }^{14}$.

While traditional disease-modifying antirheumatic drugs (DMARD) such as methotrexate appear to offer limited protection from ongoing joint damage in $\mathrm{Ps}^{15}$, a newer group of biologic agents, the tumor necrosis factor (TNF) inhibitors, can halt radiographic progression over a period of weeks to years ${ }^{16,17,18,19}$. There are currently $4 \mathrm{TNF}$ inhibitors available to Canadian physicians for treating PsA: etanercept ${ }^{17,19,20,21,22,23}$, infliximab ${ }^{18,24}$, adalimum$\mathrm{ab}^{16,25,26}$, and golimumab ${ }^{27}$. Of these biologics, etanercept has the longest record of postmarketing use in PsA, having received approval in Canada for this indication in 2004.

Etanercept, a protein construct consisting of a fully human TNF receptor fused to the Fc portion of human IgG1, acts as a competitive inhibitor of TNF signaling. Established clinical benefits of etanercept treatment in PsA include amelioration of skin disease ${ }^{19,21,22,28,29}$, reduction in joint pain and swelling ${ }^{21}$, and prevention of radiographic progression ${ }^{17,19}$. In parallel with these responses, some studies have also established significant benefits in health-related quality of life ${ }^{17,30,31}$.

Little is known of the clinical or functional outcomes of etanercept use in PsA in a real-world setting, where this biologic may be used concomitantly with other medications and in patients who might not qualify for inclusion in a randomized controlled trial (RCT). REPArE (Rating Evaluations in Psoriatic Arthritis with Enbrel) was undertaken to clarify the longterm effects of etanercept treatment in PsA in routine clinical practice. Our single-arm observational study was conducted at 22 sites in Canada. The primary efficacy endpoint of REPArE was functional improvement, as determined by the HAQ-Disability Index (HAQ-DI). Other endpoints included reduction in fatigue; changes in work ability, as measured by the HLQ ${ }^{14}$; and clinical outcomes such as changes in joint and skin symptoms and incidence of adverse events (AE). We report the clinical and functional findings in REPArE patients treated with etanercept for up to 2 years.

\section{MATERIALS AND METHODS}

Study design. Per REPArE eligibility criteria, patients were required to be $\geq 18$ years old, with active psoriasis or a history of psoriasis documented by a dermatologist. Their PsA had to be active at the time of inclusion, with $\geq 3$ swollen joints and $\geq 3$ tender/painful joints. They could have no active infection and no history of malignancy in the past 5 years, with the exception of nonmelanoma skin cancer. Patients who had received biologics were eligible following a washout of $\geq 3$ months, but all patients were required to be naive to etanercept treatment. Patients who were pregnant or nursing or who intended to become pregnant during the study period were not eligible. All study sites obtained ethics board approval for the trial.

Patients self-administered $50 \mathrm{mg}$ etanercept per week, given either as two 25-mg subcutaneous injections at separate sites on the same day or as 2 injections on separate days, 72-96 hours apart. All patients enrolled in our study were beginning therapy with commercial etanercept and may have continued taking etanercept at the completion of or withdrawal from our study at the discretion of the investigator. Nonbiologic concomitant therapies were permitted at the discretion of the investigator. Treatment compliance was assessed through direct queries at each telephone contact at Months 3, 6, 12, 18, and 24.

The primary effectiveness endpoint was the proportion of patients achieving a reduction of $\geq 0.5$ point of HAQ score over 24 months of treatment.

Secondary efficacy endpoints included change from baseline at 24 months in HLQ on 4 modules (absence from work, reduced productivity at paid work, unpaid labor production, and impediments to paid and unpaid labor); change from baseline at Month 24 for the physician and patient global assessments of disease activity; proportion with $\geq 75 \%$ improvement in Psoriasis Area and Severity Index (PASI) score at Month 24; and proportion with a Psoriatic Arthritis Response Criteria (PsARC) response at Month 24. Change from baseline in the Fatigue Severity Scale score was included as an exploratory endpoint.

Safety endpoints included nonserious and serious AE, including serious infections, nonmelanoma skin cancer, and all malignancies.

Clinical and patient-reported outcomes. Clinical status was assessed at patient visits, including baseline and Months 6, 12, 18, and 24 (end of study). Joint disease was quantified using a modification of the American College of Rheumatology joint count, documenting the number of joints with tenderness (78 joints) and swelling (76 joints). Overall disease activity was scored using the physician global assessment, a 5-point scale ranging from "very good" to "very poor." Skin severity was quantified using the PASI, which separately evaluates erythema, infiltration, and scale occurring on the head, trunk, and upper and lower extremities (range 0-72).

PsARC is a composite measure of treatment efficacy that requires improvement in at least 2 of the following measures: joint pain/tenderness, joint swelling, patient global assessment, and physician global assessment. To satisfy the PsARC responder criteria, a patient must experience an improvement in $\geq 1$ of the joint scores, and must not have worsening in any of the 4 measures.

Fatigue was quantified using the Fatigue Severity Scale, which was designed to assess the effect of fatigue on activities of daily living. The score was computed as the average response to 9 questions relating to fatigue. Responses range from 0 (not at all) to 10 (yes, completely $)^{32}$.

The $\mathrm{HLQ}^{14}$ assesses missed workdays (absenteeism), nonproductive time at work (presenteeism), patients' requirement for paid or unpaid assistance in order to manage routine activities at home, and impediments to labor. The latter were calculated on the basis of patient responses regarding 4 classes of productive activity specified in the HLQ (household work, shopping, childcare, and odd jobs $)^{14}$. The impediments score ranges from 0 (no impediments) to 8 (unable to do any of the 4 activities).

Patient-reported outcomes, including HAQ, patient global assessment of disease severity, and the Fatigue Severity score, were assessed by telephone interviews at baseline and at Months 3, 6, 12, 18, and 24. In addition, the HLQ was administered at baseline and at Months 12, 18, and 24 
Statistical methods. A modified intent-to-treat population was used for efficacy analyses in which patients were required to have received $\geq 1$ dose of etanercept, and a baseline and $\geq 1$ postbaseline efficacy measurement of the endpoint of interest. All safety analyses were performed on the safety population of patients who received $\geq 1$ dose of etanercept.

Except where otherwise stated, missing values were imputed using the last observation carried forward method. Only postbaseline values were used for imputation. Descriptive statistics are presented as mean $\pm \mathrm{SD}$ or as a percentage or, for skewed data, as median with range or interquartile range (IQR). Paired t-tests of the means were used to evaluate the significance of comparisons with baseline data, and descriptive $\mathrm{p}$ values are presented. No adjustment was made for multiplicity. Univariate logistic regression was used to identify effects on HAQ success (defined as $\geq$ 0.5-point improvement from baseline to Month 24) on baseline characteristics such as age, sex, race, duration of PsA, duration of psoriasis, and DMARD use. The relationships between productivity measured by the HLQ and HAQ and Fatigue Severity Scale were explored using regression at various timepoints as well as repeated measures of ANOVA. The HLQ outcomes were also regressed against the tender and swollen joint counts.

\section{RESULTS}

Between August 2005 and September 2007, 110 patients meeting the eligibility requirements initiated weekly etanercept treatment (50 mg/week, subcutaneous), for a period of up to 2 years. All enrolled patients received $\geq 1$ dose of etanercept.

Baseline characteristics of these patients are shown in Table 1. The REPArE study population included nearly equal numbers of men and women and was largely white,

Table 1. Baseline population characteristics $(n=110)$. Data are mean \pm SD unless otherwise indicated.

\begin{tabular}{|c|c|}
\hline Characteristic & \\
\hline \multicolumn{2}{|l|}{ Gender and ethnicity, n (\%) } \\
\hline Men/women & $54(49) / 56(51)$ \\
\hline White/other & $103(94) / 7(6)$ \\
\hline Age, yrs & $48.4 \pm 10.9$ \\
\hline Age $<65$ yrs & $105(95)$ \\
\hline \multicolumn{2}{|l|}{ Prior treatments, $\%$} \\
\hline DMARD & 89 \\
\hline NSAID & 83 \\
\hline Steroids & 46 \\
\hline Analgesics & 26 \\
\hline Phototherapy & 8 \\
\hline Tar products & 4 \\
\hline Biologics & 3 \\
\hline Emollients & 1 \\
\hline Retinoids & 1 \\
\hline Duration of psoriasis, yrs & $16.2 \pm 12.7$ \\
\hline Duration of PsA, yrs & $8.9 \pm 8.4$ \\
\hline \multicolumn{2}{|c|}{$\begin{array}{l}\text { Patients with fair, poor, or very poor } \\
\text { disease control (physician global }\end{array}$} \\
\hline assessment) $(\%)$ & 109/110 (99) \\
\hline PASI score & $4.8 \pm 7.8$ \\
\hline HAQ-DI & $1.5 \pm 0.6$ \\
\hline Joint pain/tenderness score & $30.3 \pm 20.2$ \\
\hline Joint swelling score & $18.9 \pm 13.9$ \\
\hline
\end{tabular}

HAQ-DI: Health Assessment Questionnaire Disability Index; PASI: Psoriasis Area and Severity Index; PsA: psoriatic arthritis; NSAID: nonsteroidal antiinflammatory drugs; DMARD: disease-modifying antirheumatic drugs. with a mean \pm SD age of $48.4 \pm 10.9$ years. Patients generally had longstanding psoriasis (mean duration $16.2 \pm 12.7$ years $)$ and PsA (8.9 \pm 8.4 years $)$, and a substantial majority $(89 \%)$ had used DMARD.

Per study inclusion requirements, all patients had active peripheral PsA affecting at least 3 joints. At baseline, the median number of painful/tender joints was 17.5 (IQR $11 \%-30 \%$; range 3-63), and the median number of swollen joints was 11 (IQR 7\%-16\%; range 1-39).

Patients could have active psoriasis or a history of skin involvement. Baseline PASI scores ranged from 0 to 46.8 (possible range 0-72). Among the 97 patients with active skin disease (PASI $>0$ ), the mean PASI score was 5.5 (SD 8.1 ), with a median of 2.2. Thirty-three patients (30\% of the study population) had a baseline PASI $\geq 5$, and $19(17 \%)$ had a baseline PASI $\geq 8$.

Over the course of our study, 39 patients (35\%) prematurely discontinued therapy, of whom 16 discontinued within the first year. Reasons included lack of efficacy (12 patients), AE (15), withdrawn consent, noncompliance, loss to followup, and protocol violations (12). On average, subjects in our study received $90 \%$ (SD 17.4) of the planned doses of the study drug, with a median of $96 \%$ (range $13 \%-100 \%)$.

Functional improvement with etanercept treatment. After 24 months in REPArE, patients' functional abilities improved significantly, as assessed by HAQ score. Baseline mean \pm SD HAQ was $1.50 \pm 0.56$ (range $0-2.5$, with values $\geq 1.0$ taken to define moderate to severe disability). Mean \pm SD HAQ declined to $0.90 \pm 0.68$ ( $\mathrm{p}<0.0001)$ by Month 24, with most of the improvement seen by Month 3. HAQ reduction of $\geq 0.5$ points, indicating clinically significant improvement, occurred in $56 \%$ of patients (Figure 1). HAQ reduction of $\geq 0.30$ points occurred in $64 \%$ of patients (data not shown). Moreover, $14 \%$ of patients reported a final HAQ of 0 , indicating that their disease caused them no functional impairment.

By logistic regression analysis, patient age, sex, and disease duration were not significantly associated with success at achieving a HAQ reduction of $\geq 0.50$ points (data not shown).

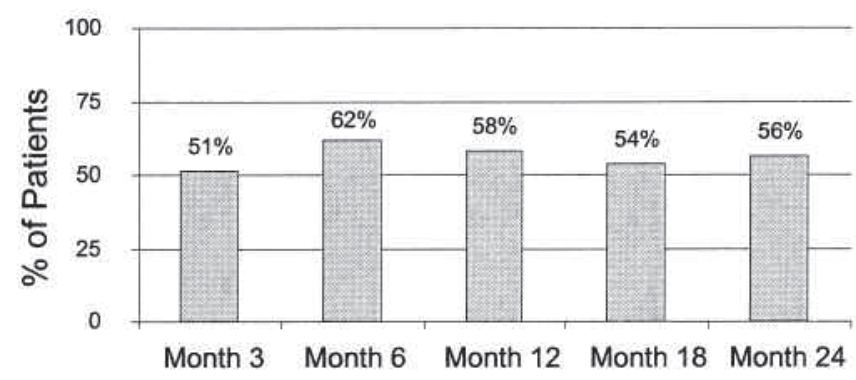

Figure 1. Proportion of patients with $\geq 0.5$-point improvement in Health Assessment Questionnaire score. The number of patients each month is 109 , except for Month 3, in which the number of patients is 108 . 
Changes in concomitant therapy with etanercept treatment. Over the course of our study, many patients decreased or eliminated their use of concomitant medications, including DMARD (methotrexate, sulfasalazine, and leflunomide), systemic corticosteroids (prednisone), and nonsteroidal antiinflammatory drugs (NSAID). Of the 62 patients using methotrexate at baseline, $26(42 \%)$ discontinued it and an additional 13 (21\%) reduced their dose. Similarly, of the 36 patients using sulfasalazine or leflunomide, 25 (69\%) discontinued DMARD treatment, while 30 of 35 patients using prednisone $(86 \%)$ discontinued corticosteroid treatment. Finally, of the 90 patients taking NSAID, 24 (27\%) discontinued regular NSAID treatment after initiating etanercept.

Clinical changes with etanercept treatment. Joint symptoms improved dramatically over the initial 6 months of our study, with median joint tenderness/pain counts declining by $70 \%$ (IQR 33\%-92\%; medians 17.5 vs 6) and median joint swelling counts declining by 67\% (IQR 40\%-93\%; medians 11 vs 3 ). This improvement was maintained over the duration of our study ( $\mathrm{p}<0.0001$ for both tender and swollen joints). Median percentage changes from baseline to Months 12, 18, and 24 were $80 \%, 75 \%$, and $74 \%$, respectively, for tenderness/pain scores and $77 \%, 82 \%$, and $80 \%$ for swelling scores.

Physician and patient global assessments of disease activity similarly improved over the first 6 months of etanercept treatment, remaining relatively stable thereafter. Over the course of our study, the proportion of patients deemed by a physician to have "poor" or "very poor" disease control declined from $23 \%$ to $8 \%$ (Figure 2). Patients' self-assessments were qualitatively similar to those of their physicians, with substantial improvement between baseline and Month 6 and little change thereafter (Figure 3). By the end of our study, none of the patients described their disease control as "very poor" (data not shown).

Treatment success as measured by the PsARC was consistent with these individual findings. By Month 6, 89/106 evaluable patients (84\%) had achieved a PsARC response. This proportion remained nearly constant over the course of our study; the proportions of PsARC responders at Months 12,18 , and 24 were $74 \%, 77 \%$, and $79 \%$, respectively.

Skin manifestations declined throughout our study period. Improvement was greatest in patients with higher baseline skin involvement. Thus, for individuals with active skin disease at baseline, PASI declined significantly $(\mathrm{p}<0.001)$ over our study period, and the median decrease was $70 \%$ (IQR 20\%-96\%). Among individuals with more severe or extensive skin involvement $(\mathrm{n}=19)$, PASI scores declined by a median of $71 \%$ (IQR 43\%-90\%; Figure 4). By the end of our study, $67 \%$ of patients with baseline skin involvement had achieved $\geq 50 \%$ reduction in PASI score (PASI 50), and 47\% had achieved PASI 75.

Table 2 shows changes in key aspects of function and work ability over the course of our study. Patient responses to the HLQ suggested reduced reliance on others to help with home activities (household work, shopping, childcare, and odd jobs around the house). Thus, comparing the 2 weeks prior to the baseline visit with the final study visit, there was a significant decline in the mean number of hours of unpaid help that patients reported using in order to take care of these home activities ( 8.0 vs 4.8 hours, $95 \% \mathrm{CI}$ of change -6.2 to $-0.2 ; p=0.0349)$. For paid help to take care of these same home activities, the trend was similar (3.2 vs $1.2,95 \%$ CI of change -6.4 to $2.6 ; p=0.3830$ ), with a large number of missing responses. The number of hours of unpaid and paid help was also found to decrease exponentially with improvement in the HAQ $(\mathrm{p}<0.001)$ and Fatigue Severity Scale score ( $\mathrm{p}$ $<0.001)$ for all timepoints. In addition, the mean HAQ score and mean tender and swollen joint count improved as impediments to work decreased ( $\mathrm{p}<0.001)$.

In parallel, impediments to labor declined significantly (3.0 vs 1.5 on an 8 -point scale, $95 \%$ CI of change -1.9 to $-1.1 ; \mathrm{p}<0.0001)$, and the mean Fatigue Severity Scale score

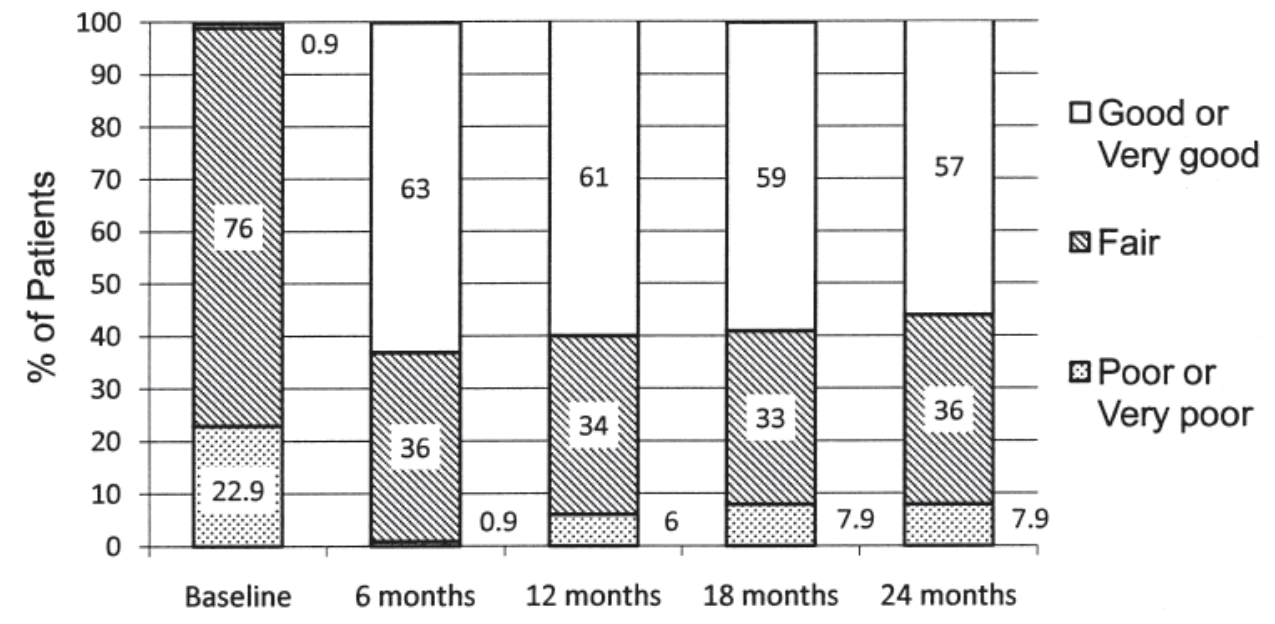

Figure 2. Change in distribution of physician global assessments over the course of the trial. 


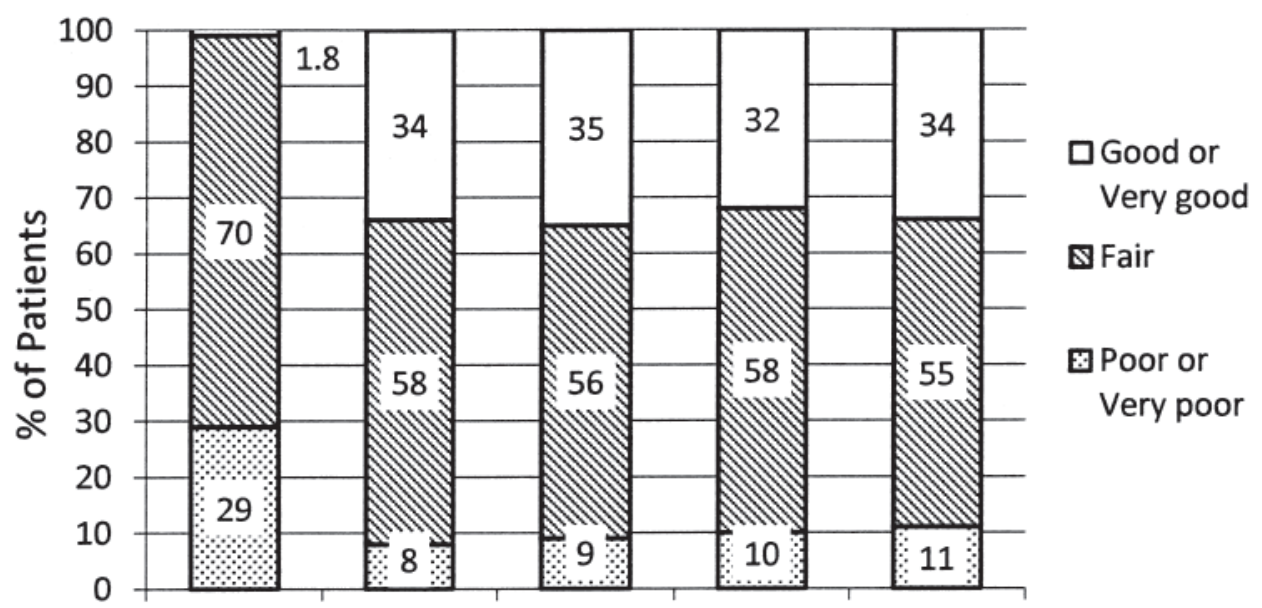

Baseline 6 months 12 months 18 months 24 months

Figure 3. Change in distribution of patient global assessments over the course of the trial.

Month

6 12 18 24

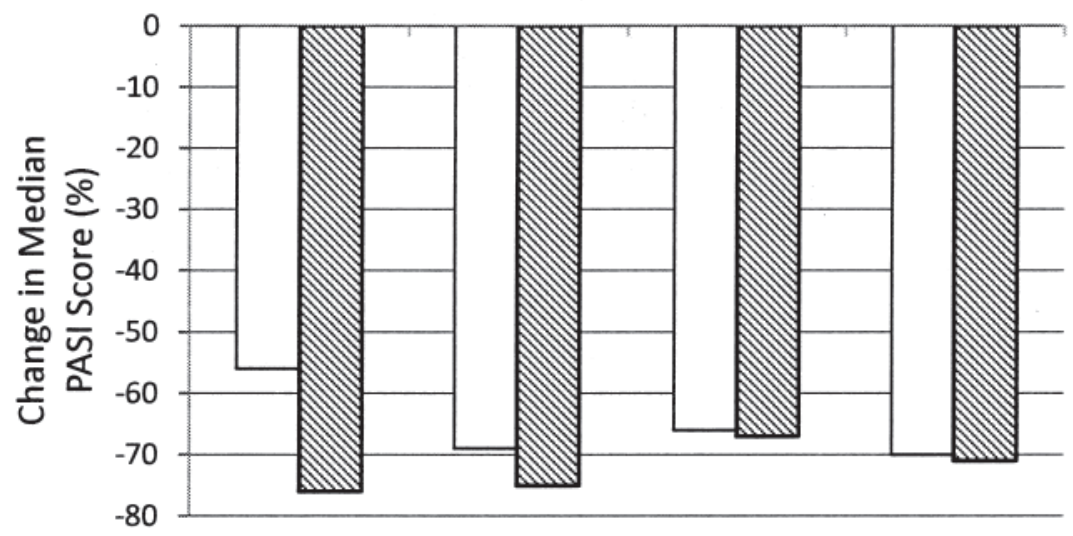

$\square$ Baseline > $0(n=97)$

$\mathbb{N}$ Baseline $\geq$

$8(n=19)$

Figure 4. Change in median Psoriasis Area and Severity Index (PASI) score over time. PASI score reduction was calculated separately for patients with active skin disease.

Table 2. Changes in function and patient work productivity with etanercept treatment. Except for Fatigue Severity Scale, values apply to the 2-week period prior to the baseline or Month 24 visit.

\begin{tabular}{lccccc}
\hline Productivity Measures & $\mathrm{n}^{*}$ & Baseline Mean & Month 24 Mean & Mean Change (SD) & $\mathrm{p}$ \\
\hline Absence from work (working days) & 40 & 0.7 & 0.3 & $0.4(2.6)$ & 0.3436 \\
Unpaid work** by paid help (hours) & 27 & 3.2 & 1.2 & $1.9(11.4)$ & 0.3830 \\
Unpaid work** by unpaid help (hours) $^{\dagger}$ & 66 & 8.0 & 4.8 & $3.2(12.1)$ & 0.0349 \\
Impediments to paid and unpaid labour $^{\dagger}$ & 71 & 3.0 & 1.5 & $1.5(1.7)$ & $<0.001$ \\
Fatigue Severity Scale $^{\dagger \dagger}$ & 109 & 6.36 & 4.75 & $1.62(2.33)$ & $<0.001$ \\
\hline
\end{tabular}

* Subjects with available data at both baseline and Month 24. ** Unpaid work defined as household work, shopping, childcare, and odd jobs around the house. ${ }^{\dagger}$ Score out of $8(0=$ no impediments; $8=$ unable to do any of 4 surveyed activities). ${ }^{\dagger}$ Average of 9 questions relating to fatigue; score out of $10(0=$ not at all; $10=$ yes, completely).

declined significantly (6.4 vs 4.8 on a 10 -point scale, $95 \%$ CI of change -2.1 to $-1.2 ; \mathrm{p}<0.0001)$.

Safety and tolerability of etanercept treatment. Table 3 iden- tifies the most common AE reported over the 2-year course of our study. Nasopharyngitis was the most common AE, occurring in 20/110 individuals (18.2\%). 
Table 3. Adverse events reported by $>5 \%$ of subjects.

\begin{tabular}{lc}
\hline Adverse Event & $\mathrm{n}(\%)$ \\
\hline Nasopharyngitis & $20(18.2)$ \\
Upper respiratory tract infection & $15(13.6)$ \\
Injection site reaction & $13(11.8)$ \\
Headache & $12(10.9)$ \\
Influenza-like illness & $11(10.0)$ \\
Sinusitis & $11(10.0)$ \\
Diarrhea & $7(6.4)$ \\
Hypertension & $7(6.4)$ \\
Arthralgia & $6(5.5)$ \\
Cough & $6(5.5)$ \\
Pharyngolaryngeal pain & $6(5.5)$ \\
\hline
\end{tabular}

Twenty serious AE (SAE) were reported, occurring in 14 subjects. SAE of interest, as specified in the study protocol (i.e., malignancies and serious infections), included 2 cases of sinusitis and 1 case each of the following: abdominal abscess, appendicitis, malignant lung neoplasm, malignant melanoma in situ, malignant pleural effusion, viral pneumonia, and streptococcal infection. Other SAE included single cases of angina pectoris, cardiac arrest, cerebral hemorrhage, cervical vertebral fracture, fibula fracture, myocardial infarction, osteoarthritis, ovarian cyst, scleroderma, tibia fracture, and umbilical hernia. The most frequently reported $\mathrm{AE}$ leading to withdrawal from the study was rash, which occurred in 2 patients. A total of $20 \mathrm{AE}$ were reported by the 15 patients who withdrew from the study because of $\mathrm{AE}$, with only 6 of these $\mathrm{AE}$ considered related to the study drug.

Two deaths were reported in patients after they had withdrawn from our study, 1 resulting from lung cancer and the other from cardiac arrest and cerebral hemorrhage. These deaths were not considered related to etanercept treatment.

\section{DISCUSSION}

The Group for Research and Assessment of Psoriasis and Psoriatic Arthritis (GRAPPA) treatment guidelines identify 5 distinct aspects of PsA (peripheral arthritis, skin disease, spinal disease, enthesitis, and dactylitis) that may be evaluated independently in managing the disease ${ }^{33}$. TNF inhibitor treatment, which significantly ameliorates each of these disease aspects ${ }^{28,34}$, is associated with reduced disability and improvements in multiple aspects of the quality of life $\mathrm{e}^{35}$.

The clinical benefits of etanercept are well established with regard to peripheral joint disease and skin symptoms $17,20,21,22,23,29$. Thus, in pivotal trials, 12-week treatment with etanercept led to significant increases, relative to placebo, in the proportion of patients with PsA achieving the PsARC and PASI 75-level skin clearance. Longer-term studies confirmed that cutaneous and articular benefits with etanercept were sustained over $\geq 2-3$ years ${ }^{19,21}$. Etanercept treatment has been studied in 6-month RCT as well as in open-label studies. Despite the greater constraints on the patient population in the former and the longer study durations in the latter studies, a consistent picture of etanercept's safety and efficacy has emerged from this literature. PsARC response has been reported in about $70 \%-87 \%$ of patients within 6 months of etanercept treatment ${ }^{17,19,22,23,36}$. Where PsARC data are available, it appears that the bulk of the response occurs within the initial 4-12 weeks of treatment ${ }^{17,22,36}$ and is maintained for periods of $\geq 2$ years ${ }^{19}$. Patients with PsA have also been reported to decrease their use of NSAID and other analgesic drugs significantly ${ }^{36}$.

Common AE such as upper respiratory tract infections and headache appear to occur at similar rates in placebo-treated compared to etanercept-treated patients. Etanercept discontinuation because of safety concerns has occurred rarely $19,30,37$ or not at all ${ }^{29,36}$ in available studies, although British patient registry data suggested that about $3 \%$ of patients discontinued etanercept per year, citing $\mathrm{AE}^{38}$.

The current findings from REPArE, which included patients from routine clinical care settings, are consistent with this literature. Each of the clinical variables studied, including patient and physician global assessments, PsARC response, and PASI score, showed substantial and statistically significant improvement by Month 6 . In each instance, these benefits were sustained throughout the study period, although skin symptoms appeared to improve further between Months 6 and 24. In the current study, 79\% of patients were PsARC responders, and median PASI scores declined by $64 \%$. No new AE were reported, and withdrawal because of AE occurred in 15/110 patients (14\%) over the course of 2 years.

Most patients who were using DMARD or prednisone at baseline were able to discontinue or reduce their dose of these concomitant medications. In particular, use of concomitant prednisone declined by $86 \%$ over the course of our study.

REPArE patients showed significant disability at baseline, with HAQ scores ranging from 0 to 2.5. Indeed, baseline disability in our study (mean \pm SD HAQ, $1.5 \pm 0.6$ ) was greater than has been reported in most other studies of TNF inhibitors in PsA, including comparison trials ${ }^{28}$ and studies of etanercept ${ }^{30,39}$, infliximab ${ }^{18}$, and adalimumab ${ }^{25,40}$.

For instance, in a 6-month study of 1122 American patients with PsA who were treated with etanercept, Frankel, et al reported a mean HAQ score of 0.8 at baseline. Mean HAQ declined to 0.4 over 6 months, with $47 \%$ of patients attaining a HAQ score of 0 (i.e., no functional impairment) by the end of the study ${ }^{30}$. In contrast, among REPArE patients, $14 \%$ reported no disability by the end of the study, suggesting a greater burden of disease in the REPArE study population at baseline. In other respects, however, functional improvement in REPArE and in the study by Frankel, et $a l^{30}$ followed a similar trajectory: sub- 
stantial HAQ score reduction occurred within 3 months of initiating etanercept treatment, with further reduction seen by Month 6. In REPArE, mean HAQ scores remained stable at 0.9 after Month 6. Fifty-six percent of patients experienced a reduction of HAQ score by $\geq 0.50$ point, the predetermined cutoff for clinically significant improvement, which is well above the minimally clinically significant decrease of 0.30 determined for PsA ${ }^{16}$. Again, most of this functional improvement was evident within the first 6 months of initiating etanercept. Comparable improvements in HAQ scores with etanercept were also recently reported by Mease, $e t a l^{39}$.

Recently developed minimal disease activity criteria in $\mathrm{PsA}^{41}$ could not be calculated in our study since not all of the outcome measures were collected.

Several other studies have discussed patient work productivity in PsA $7,11,42,43$ but to our knowledge, REPArE is the first to examine longterm changes in work productivity with ongoing TNF inhibitor treatment. We found that etanercept treatment was associated with a nonsignificant trend toward reduced absenteeism at work. In addition, REPArE patients showed a statistically significant reduction in impediments to labor and in their use of unpaid help to manage ordinary household tasks. In parallel, patients' fatigue scores declined significantly.

Etanercept was safe and well tolerated, with few serious $\mathrm{AE}$ and no new safety signals emerging from the REPArE study population. Of the 110 patients in the REPArE study population, $71(65 \%)$ continued taking etanercept throughout the 24-month study; similar levels of patient persistence have been reported in studies of British ${ }^{38}$ and Greek ${ }^{24}$ patients with PsA who received TNF therapy for 2-3 years.

Limitations of REPArE are shared with other single-arm, open-label studies. Because of this trial design, we cannot estimate the extent to which regression to the mean may have contributed to the observed clinical and functional changes. However, the benefits we see are long-lived and reflect other findings in the literature on etanercept, including those from placebo-controlled trials. Nor can we formally exclude the possibility of bias in assessing the patients' medical status, although the consistency of results seen in patient versus physician global assessments suggests that the benefits we documented were real and meaningful to our patients. Finally, because of missing data on some patient-reported outcomes, the significance/nonsignificance of some functional changes cannot be assigned with confidence. We note, however, that the functional changes and changes in work productivity that we observed were consistent with a significant decrease in fatigue.

Our 2-year study suggests that continuous treatment with etanercept $(50 \mathrm{mg} /$ week) in a clinical setting can improve the cutaneous and articular symptoms of PsA while reducing fatigue, improving work productivity, and ameliorating or eliminating disability.

\section{ACKNOWLEDGMENT}

The authors thank John Ashkenas, PhD, (SCRIPT, Toronto) for assistance in preparing this report.

The list of REPArE principal investigators: Vandana Ahluwalia, Brampton, ON; Christopher Atkins, Victoria, BC; Sangeeta Bajaj, Brampton, ON; Murray Baron, Montreal, QC; Mary Bell, Toronto, ON; William Bensen, Hamilton, ON; Ken Blocka, Vancouver, BC; Vivian Bykerk, Toronto, ON; Monique Camerlain, Sherbrooke, QC; George Ecker, Fredericton, NB; Rafat Faraawi, Kitchener, ON; Dafna Gladman, Toronto, ON; Boulos Haraoui, Montreal, QC; Mark Hazeltine, Laval, QC; James Henderson, Fredericton, NB; Anna Jaroszynska, Burlington, ON; Suneil Kapur, Concord, ON; Arthur Karasik, Toronto, ON; Majed Khraishi, St. John's, NL; Timothy McCarthy, Winnipeg, MB; Patricia Morassut, Nepean, ON; Frederick Morin, Trois-Rivieres, QC; Bindu Nair, Saskatoon, SK; Proton Rahman, St. John's, NL; Jude Rodrigues, Windsor, ON; Jan Schulz, Montreal, QC; Brent Thomson, Winnipeg, MB; Carter Thorne, Newmarket, ON; Jerieta Waltin-James, Ottawa, ON.

\section{REFERENCES}

1. Gladman DD. Psoriatic arthritis. In: Koo J, Lee CS, Lebwoh LM, Weinstein GD, Gottlieb AB, editors. Moderate to severe psoriasis. 3rd ed. New York: Informa Health Care; 2009:239-58.

2. Rahman P, Nguyen E, Cheung C, Schentag CT, Gladman DD. Comparison of radiological severity in psoriatic arthritis and rheumatoid arthritis. J Rheumatol 2001;28:1041-4.

3. O'Reilly D, Rahman P. Evaluation for psoriatic athritis in dermatology clinics. J Cutan Med Surg 2009;13 Suppl 2:S88-92.

4. Canadian Dermatology Association. Canadian Psoriasis Guidelines Committee. Canadian Guidelines for the Management of Plaque Psoriasis, June 2009. [Internet. Accessed Feb 8, 2011.] Available from: www.dermatology.ca/psoriasisguidelines

5. Gelfand JM, Gladman DD, Mease PJ, Smith N, Margolis DJ, Nijsten T, et al. Epidemiology of psoriatic arthritis in the population of the United States. J Am Acad Dermatol 2005;53:573.

6. Lynde CW, Poulin Y, Guenther L, Jackson C. The burden of psoriasis in Canada: insights from the pSoriasis Knowledge IN Canada (SKIN) survey. J Cutan Med Surg 2009;13:235-52.

7. Radtke MA, Reich K, Blome C, Rustenbach S, Augustin M. Prevalence and clinical features of psoriatic arthritis and joint complaints in 2009 patients with psoriasis: results of a German national survey. J Eur Acad Dermatol Venereol 2009;23:683-91.

8. Salaffi F, Carotti M, Gasparini S, Intorcia M, Grassi W. The health-related quality of life in rheumatoid arthritis, ankylosing spondylitis, and psoriatic arthritis: a comparison with a selected sample of healthy people. Health Qual Life Outcomes 2009;7:25-37.

9. Husted JA, Gladman DD, Farewell VT, Cook RJ. Health-related quality of life of patients with psoriatic arthritis: a comparison with patients with rheumatoid arthritis. Arthritis Rheum 2001;45:151-8.

10. Husted JA, Gladman DD, Farewell VT, Long JA, Cook RJ Validating the SF-36 health survey questionnaire in patients with psoriatic arthritis. J Rheumatol 1997;24:511-7.

11. Wallenius M, Skomsvoll JF, Koldingsnes W, Rodevand E, Mikkelsen K, Kaufmann C, et al. Work disability and health-related quality of life in males and females with psoriatic arthritis. Ann Rheum Dis 2009;68:685-9.

12. Gladman DD, Mease PJ, Krueger G, van der Heidje DM, Antoni C, Helliwell PS, et al. Outcome measures in psoriatic arthritis. J Rheumatol 2005;32:2262-9.

13. Husted JA, Tom BD, Farewell VT, Schentag CT, Gladman DD. Description and prediction of physical functional disability in psoriatic arthritis: a longitudinal analysis using a Markov model approach. Arthritis Rheum 2005;53:404-9.

14. van Roijen L, Essink-Bot ML. The Health and Labour Questionnaire (manual). [Internet. Accessed Feb 8, 2011.] Available 
from: www.imta.nl/publications/0052.html

15. Gladman DD. Management of psoriatic arthritis. In: Weisman MH, Weinblatt ME, Louie JS, van Vollenhaven RF, editors. Targeted treatment of rheumatic disease. 1st ed. Philadelphia: Saunders Elsevier; 2010:55-69.

16. Mease PJ, Ory P, Sharp JT, Ritchlin CT, Van den Bosch F, Wellborne F, et al. Adalimumab for long-term treatment of psoriatic arthritis: 2-year data from the Adalimumab Effectiveness in Psoriatic Arthritis Trial (ADEPT). Ann Rheum Dis 2009;68:702-9.

17. Mease PJ, Kivitz AJ, Burch FX, Siegel EL, Cohen SB, Ory P, et al. Etanercept treatment of psoriatic arthritis: safety, efficacy, and effect on disease progression. Arthritis Rheum 2004;50:2264-72.

18. Antoni CE, Kavanaugh A, van der Heijde D, Beutler A, Keenan G, Zhou B, et al. Two-year efficacy and safety of infliximab treatment in patients with active psoriatic arthritis: findings of the Infliximab Multinational Psoriatic Arthritis Controlled Trial (IMPACT). J Rheumatol 2008;35:869-76.

19. Mease PJ, Kivitz AJ, Burch FX, Siegel EL, Cohen SB, Ory P, et al. Continued inhibition of radiographic progression in patients with psoriatic arthritis following 2 years of treatment with etanercept. J Rheumatol 2006;33:712-21.

20. Gottlieb AB, Kircik L, Eisen D, Jackson JM, Boh EE, Strober BE, et al. Use of etanercept for psoriatic arthritis in the dermatology clinic: the Experience Diagnosing, Understanding Care, and Treatment with Etanercept (EDUCATE) study. J Dermatolog Treat 2006;17:343-52.

21. Mazzotta A, Esposito M, Schipani C, Chimenti S. Long-term experience with etanercept in psoriatic arthritis patients: a 3-year observational study. J Dermatolog Treat 2009;20:354-8.

22. Mease PJ, Goffe BS, Metz J, VanderStoep A, Finck B, Burge DJ. Etanercept in the treatment of psoriatic arthritis and psoriasis: a randomised trial. Lancet 2000;356:385-90.

23. Sterry W, Ortonne JP, Kirkham B, Brocq O, Robertson D, Pedersen $\mathrm{RD}$, et al. Comparison of two etanercept regimens for treatment of psoriasis and psoriatic arthritis: PRESTA randomised double blind multicentre trial. BMJ 2010;340:c147.

24. Voulgari PV, Venetsanopoulou AI, Exarchou SA, Alamanos Y, Tsifetaki N, Drosos AA. Sustained clinical response and high infliximab survival in psoriatic arthritis patients: a 3-year long-term study. Semin Arthritis Rheum 2008;37:293-8.

25. Gladman DD, Mease PJ, Ritchlin CT, Choy EH, Sharp JT, Ory PA, et al. Adalimumab for long-term treatment of psoriatic arthritis: forty-eight week data from the Adalimumab Effectiveness in Psoriatic Arthritis Trial. Arthritis Rheum 2007;56:476-88.

26. Van den Bosch F, Manger B, Goupille P, McHugh N, Rodevand E, Holck $\mathrm{P}$, et al. Effectiveness of adalimumab in treating patients with active psoriatic arthritis and predictors of good clinical responses for arthritis, skin and nail lesions. Ann Rheum Dis 2010;69:394-9.

27. Kavanaugh A, McInnes I, Mease P, Krueger GG, Gladman D, Gomez-Reino J, et al. Golimumab, a new human tumor necrosis factor alpha antibody, administered every four weeks as a subcutaneous injection in psoriatic arthritis: twenty-four-week efficacy and safety results of a randomized, placebo-controlled study. Arthritis Rheum 2009;60:976-86.

28. Atteno M, Peluso R, Costa L, Padula S, Iervolino S, Caso F, et al. Comparison of effectiveness and safety of infliximab, etanercept, and adalimumab in psoriatic arthritis patients who experienced an inadequate response to previous disease-modifying antirheumatic drugs. Clin Rheumatol 2010;29:399-403.
29. Mazzotta A, Esposito M, Costanzo A, Chimenti S. Efficacy and safety of etanercept in psoriasis after switching from other treatments: an observational study. Am J Clin Dermatol 2009;10:319-24.

30. Frankel EH, Strober BE, Crowley JJ, Fivenson DP, Woolley JM, Yu $\mathrm{EB}$, et al. Etanercept improves psoriatic arthritis patient-reported outcomes: results from EDUCATE. Cutis 2007;79:322-6.

31. Olivieri I, de Portu S, Salvarani C, Cauli A, Lubrano E, Spadaro A, et al. The psoriatic arthritis cost evaluation study: a cost-of-illness study on tumour necrosis factor inhibitors in psoriatic arthritis patients with inadequate response to conventional therapy. Rheumatology 2008;47:1664-70.

32. Husted JA, Tom BD, Schentag CT, Farewell VT, Gladman DD. Occurrence and correlates of fatigue in psoriatic arthritis. Ann Rheum Dis 2009;68:1553-8.

33. Ritchlin CT, Kavanaugh A, Gladman DD, Mease PJ, Helliwell P, Boehncke WH, et al. Treatment recommendations for psoriatic arthritis. Ann Rheum Dis 2009;68:1387-94.

34. Kavanaugh A, Tutuncu Z, Catalan-Sanchez T. Update on anti-tumor necrosis factor therapy in the spondyloarthropathies including psoriatic arthritis. Curr Opin Rheumatol 2006;18:347-53.

35. Heiberg MS, Koldingsnes W, Mikkelsen K, Rodevand E, Kaufmann C, Mowinckel P, et al. The comparative one-year performance of anti-tumor necrosis factor alpha drugs in patients with rheumatoid arthritis, psoriatic arthritis, and ankylosing spondylitis: results from a longitudinal, observational, multicenter study. Arthritis Rheum 2008;59:234-40.

36. de Vlam K, Lories RJ. Efficacy, effectiveness and safety of etanercept in monotherapy for refractory psoriatic arthritis: a 26-week observational study. Rheumatology 2006;45:321-4.

37. Brodszky V, Pentek M, Gulacsi L. Efficacy of adalimumab, etanercept, and infliximab in psoriatic arthritis based on ACR50 response after 24 weeks of treatment. Scand J Rheumatol 2008;37:399-400.

38. Saad AA, Ashcroft DM, Watson KD, Hyrich KL, Noyce PR, Symmons DP. Persistence with anti-tumour necrosis factor therapies in patients with psoriatic arthritis: observational study from the British Society of Rheumatology Biologics Register. Arthritis Res Ther 2009;11:R52-61.

39. Mease P, Woolley M, Singh A, Tsuji W, Dunn M, Chiou C. Patient-reported outcomes in a randomized trial of etanercept in psoriatic arthritis. J Rheumatol 2010;37:1221-7.

40. Gladman DD, Mease PJ, Cifaldi MA, Perdok RJ, Sasso E, Medich J. Adalimumab improves joint-related and skin-related functional impairment in patients with psoriatic arthritis: patient-reported outcomes of the Adalimumab Effectiveness in Psoriatic Arthritis Trial. Ann Rheum Dis 2007;66:163-8.

41. Coates LC, Fransen J, Helliwell PS. Defining minimal disease activity in psoriatic arthritis: A proposed objective target for treatment. Ann Rheum Dis 2010;69:46-53.

42. Ackermann C, Kavanaugh A. Economic burden of psoriatic arthritis. Pharmacoeconomics 2008;26:121-9.

43. Kavanaugh A, Antoni C, Mease P, Gladman D, Yan S, Bala M, et al. Effect of infliximab therapy on employment, time lost from work, and productivity in patients with psoriatic arthritis. J Rheumatol 2006;33:2254-9. 